\title{
Live Colonocytes in Newborn Stool: Surrogates for Evaluation of Gut Physiology and Disease Pathogenesis
}

\author{
DINESH S. CHANDEL, GHEORGHE T. BRAILEANU, JUNE-HOME J. CHEN, HEGANG H. CHEN, AND PINAKI PANIGRAHI
}

\begin{abstract}
Department of Environmental, Agricultural and Occupational Health [D.S.C.], Department of Pediatrics and Epidemiology [P.P.], Center for Global Health and Development, College of Public Health, University of Nebraska Medical Center, Omaha, Nebraska 68198; Department of Pediatrics [G.T.B.], Department of Epidemiology and Preventive Medicine [H.H.C.], University of Maryland School of Medicine, Baltimore, Maryland 21201; Emergent Biosolution [J.-H.J.C.], Gaithersburg, Maryland 20878
\end{abstract}

\begin{abstract}
Studies of gastrointestinal pathophysiology are not feasible by biopsies in human neonates. We examined the utility of live colonocytes in stool in studying cellular markers during early neonatal life. Expression of $\mathrm{IgA}, \mathrm{IgG}$, cluster of differentiation-45 cells (CD45), and toll-like receptors-2 and 4 (TLR2 and TLR4) were analyzed by flow cytometry. Colonocyte RNA extracts were used in quantitative real-time PCR (qRT-PCR) to examine the expression of cytokeratin-19, ribosomal protein-24, and tight-junction $(\mathrm{Tj})$ protein zonula occludens-1 (ZO-1). Colonocyte yield varied between $5 \times$ $10^{4}$ to $2 \times 10^{6}$ cells/g of stool. Meconium samples yielded a highly enriched population of viable cells. Although low, all samples showed CD45-positive cells during the initial weeks of life. Starting as early as d 2, IgA expression was observed in $69 \%$ of the cells. Low to moderate expression of IgG was observed with a linear increase as the infants grew. There was an almost total lack of TLR2 staining; however, $>55 \%$ of the colonocytes showed TLR 4 expression. Although high levels of IgA in gut cells may serve as a natural protectant during neonatal period, increased TLR4 may provide a niche for lipopolysaccharide (LPS)-mediated epithelial damage. Use of stool colonocytes can be a valuable noninvasive approach for studying gut pathophysiology in the neonatal period. (Pediatr Res 70: 153-158, 2011)
\end{abstract}

$S^{n}$ udies involving gut pathophysiology have traditionally relied on tissue biopsies. Because of the invasiveness, this method is largely unacceptable in human neonates and has thus limited our ability for further scientific exploration and elucidation of mechanisms of disease. Although bulk of information derives from postmortem samples and animal models, prospective and systematic examination of pathophysiologic changes in human neonates have been greatly hampered. Apart from diseases of genetic origin and intrauterine malformations, many other conditions of infectious and inflammatory consequences such as necrotizing enterocolitis (NEC) in premature infants have only been studied after the full-blown manifestation of disease (e.g. after surgery) leaving the steps of disease progression and pathogenesis largely unexplored.

Studying gut cellular markers using exfoliated colonocytes described earlier (1-3) has now gained renewed interest be-

Received January 5, 2011; accepted February 23, 2011.

Correspondence: Pinaki Panigrahi, M.D., Ph.D., Department of Pediatrics and Epidemiology, Center for Global Health and Development, College of Public Health, University of Nebraska Medical Center, 984385 Nebraska Medical Center, Omaha, NE 68198-4385; e-mail: ppanigrahi@unmc.edu

Supported, in part, by the NIH grant RO1HD53719. cause of its noninvasive nature. The concept originated $>50 \mathrm{y}$ ago, but the initial procedure to obtain cells for cytological diagnosis by colorectal irrigation seemed too complicated (4) and was abandoned. During early 90s, Nair et al. described a noninvasive procedure to obtain colonocytes from adult stool using Percoll-density gradient centrifugation. The technique allowed recovery of several millions $\left(>40 \times 10^{6} / \mathrm{g}\right.$ stool $)$ of viable human colonic cells suitable for investigational or diagnostic purposes because they reflected immediate history of the gut and its metabolic function (5). Since then, several modifications have been made in the collection medium and purification steps $(6,7)$. Recently, there were attempts to separate colonocytes from stool using immunomagnetic beads covered with antibody against specific epithelial cell proteins $(3,8)$. Multiple studies have shown feasibility of the colonocyte technique in studying molecular biomarkers of colon cancer $(6,7)$, cancer diagnostics and pathogenesis (9), detection of $p 53$ gene mutations $(1,10)$, and evaluation of the action of bioactive food components on gut epithelia (2).

With the advent of modern molecular techniques during the recent past, there has been growing interests in purifying high-quality RNA from colonocytes to gain insights of in vivo gene expression patterns $(11,12)$. Several studies have reported on this front. In a study by Davidson et al. (11), real-time PCR (RT-PCR) analysis of mRNA isolated from exfoliated colonocytes was used effectively to monitor early stage colon cancers and chronic inflammation. Another study involving viable colonocytes isolated from adult stool demonstrated disease-related gene expression patterns in vivo (13). However, studies in human neonates, where such approaches may have the maximum benefit, have received extremely limited attention $(3,14)$. In the current study, an attempt was made to isolate and examine colonocytes from infant stools during early neonatal life. To the best of our knowledge, this is the first report describing isolation of large number of viable colonocytes from meconium samples and utility of these cells in flow cytometry for elucidation of surface markers and recovery of RNA amenable for further molecular studies.

\footnotetext{
Abbreviations: CD45, Cluster of differentiation-45 cells; LPS, lipopolysaccharide; qRT-PCR, quantitative real-time PCR; TLR2/4, toll-like receptor 2 or 4 ; ZO-1, zonula occludens-1 [a tight junction (Tj)-protein]
} 
Table 1. DNA sequence of primer pairs used to study human colonocyte genes

\begin{tabular}{|c|c|c|c|}
\hline Genes amplified & Description & Primer sequence* & $\begin{array}{l}\text { qRT-PCR } \\
(n=\text { cycles })\end{array}$ \\
\hline Ribosomal protein- 24 & Cytoplasmic, 40s ribosomal protein encoded by RPS24-gene & $\begin{array}{l}\text { F: 5'-GATGTCATCTTTGTATTTGGATTC-3' } \\
\text { R: 5'-GTCCCCCTGACCTTCTTCATTCTG-3' }\end{array}$ & 16 \\
\hline Cytokeratin-19 & $\begin{array}{l}\text { A biomarker, used in RT-PCR detection of tumor cells } \\
\text { disseminated in lymph nodes, blood and bone-marrow, } \\
\text { and to differentiate cells of epithelial origin, encoded by } \\
\text { KRT19-gene }\end{array}$ & $\begin{array}{l}\text { F: 5'-ATCCTGAGTGACATGCGAAGC-3' } \\
\text { R: 5'-CATGAGCCGCTGGTACTCCTG-3' }\end{array}$ & 18 \\
\hline $\mathrm{ZO}-1$ & Intercellular tight junction protein-1, encoded by TJP1-gene & $\begin{array}{l}\text { F: 5'-CGGTCCTCTGAGCCTGTAAG-3' } \\
\text { R: 5'-GGATCTACATGCGACGACAA-3' }\end{array}$ & 20 \\
\hline
\end{tabular}

* $\mathrm{F}$, forward; $\mathrm{R}$, reverse.

\section{MATERIALS AND METHODS}

Patients and samples. Random stool samples $(0.5-1.0 \mathrm{~g})$ were collected from diapers of 59 infants admitted to the NICU or step-down unit at University of Maryland Medical Center. Patient identifiers were removed except the GA and age of the baby. The NICU staff collecting samples were not involved in the laboratory analysis. Previous informed consents were obtained from one parent, and the study was approved by the institutional review board (IRB) at University of Maryland. Although the collection was random, an attempt was made to have samples spread over a wide range of GA (24-40 wk) and days of life in the first month. Sample collection was stopped, after banking multiple samples for age groups ranging from d 2 to 4 (meconium), $7( \pm 2), 14( \pm 3), 21( \pm 3), 28( \pm 3)$, and $60( \pm 5) \mathrm{d}$. Detailed flow cytometry analysis was done on a subset of samples representing these age groups.

Isolation of live colonocytes. Samples were processed using a commercially available kit (Noninvasive technologies Inc., Elkridge, MD) with subtle modifications in collection and purification steps. Briefly, $0.5 \mathrm{~g}$ of fresh stool scraped from infant diapers was thoroughly suspended (vortexed after adding 5-6 glass beads) in a cell transport medium (at room temperature) within $1 \mathrm{~h}$ of collection. The resulting mix was sequentially filtered through a $330-\mu \mathrm{m}$ nylon mesh and a $40-\mu \mathrm{m}$ filter cap into a $50-\mathrm{mL}$ centrifuge tube and subjected to Percoll-density gradient centrifugation as per kit protocol. Because of the interfering precipitates (casein-rich breast milk diet of the newborns) masking the supernatant layers, repeat stringent PBS washes were added to the protocol for effective purification and yield. An aliquot from purified cell suspension was counted after Trypan-blue exclusion under a phase-contrast microscope using a hemocytometer to distinguish the viable cell population from necrotic ones. The meconium, however, because of the sticky and stretchable texture, was difficult to process requiring extra homogenization and filtration steps. Apart from the interface (as recommended by the manufacturer), we retained the upper mucous layer and subjected it to repeat PBS wash and further gradient purifications. Separate aliquots of purified colonocytes were stored frozen $\left(-80^{\circ} \mathrm{C}\right)$ in a cell-freezing medium until further use in flow cytometry and also instantly suspended in RNeasy buffer before freezing for future RNA purification and gene expression analysis.

Flow cytometry for IgA, IgG, cluster of differentiation-45 cells (CD45), and toll-like receptors 2 and 4. Flow cytometry assays and staining for surface antigens on isolated colonocytes were performed as described previously (1). For direct staining of CD45, IgA, and IgG, the fluorescent-labeled primary antibody (Santa Cruz Biotechnology Inc., Santa Cruz, CA) was added to the cells and incubated at room temperature for $15 \mathrm{~min}$ ( $\operatorname{IgA}$ and $\operatorname{IgG}$ ) or at $4{ }^{\circ} \mathrm{C}$ for $60 \mathrm{~min}$ for $\mathrm{CD} 45$. For indirect staining for toll-like receptors 2 and 4 (TLR2 and TLR4), cells were initially stained with unlabeled primary antibody and treated with fluorescent secondary antibody. The cells were washed twice in $1 \%$ BSA (PBS) to remove unbound antibody conjugate and resuspended in the same buffer for flow cytometry analysis (BD FACS Calibur; Becton Dickinson Immunocytometry Systems, San Jose, CA).

Isolation of total RNA from colonocytes and mRNA purification. Frozen aliquots of isolated colonocytes suspended in RNeasy buffer were processed for RNA purification using a kit protocol previously applied in adult samples (12). However, suboptimal RNA yield and contaminating bacterial RNA prompted us to include subtle modifications before mRNA enrichment. Samples were subjected to mRNA purification using Oligotex mRNA-mini kit (Qiagen Inc., Valencia, CA) to obtain optimal quality mRNA yield suitable for quantitative real-time PCR (qRT-PCR) analysis.

Quantitative real-time PCR. Quantitative RT-PCR analysis was done for selected genes using our previously described methods (15). Briefly, $100 \mathrm{ng}$ of total RNA from each sample was reverse transcribed using the SuperScriptIII first Strand Synthesis Supermix for qRT-PCR (Invitrogen, Carlsbad, CA). SYBR Green JumpStart Taq ReadyMix Kit (Sigma Chemical Co., Saint
Louis, MO) was applied using an iCycler iQ RT-PCR detection System (Bio-Rad, Hercules, CA). Using colonocyte mRNA from infants (d 2/4, 7, 14 , and 28), we amplified the eukaryotic genes: cytokeratin-19: an epithelial cell marker; zonula occludens-1 (ZO-1): a tight junction (Tj) protein; and the ribosomal protein-24: a house keeping mammalian gene. Table 1 lists the primer sets used to amplify these genes for this study. The PCR program included a preincubation step at $95^{\circ} \mathrm{C}$ for $15 \mathrm{~min}$ to activate the Taqpolymerase before 45 cycles of denaturation $\left(94^{\circ} \mathrm{C}\right)$, annealing $\left(56^{\circ} \mathrm{C}\right)$, and extension $\left(72^{\circ} \mathrm{C}\right)$ each for $30 \mathrm{~s}$. Samples were tested in triplicate, and RNA from cultured Caco-2 cells was also included as positive control.

Statistical analysis. To investigate the association between time and expression of surface markers (and colonocyte yield), we used a straight-line regression model with each marker expression as dependent variable and time as independent variable. A linear trend was indicated when the test of slope was significant $(p<0.05)$. Data analyses were performed using statistics analysis software SAS version 9.2.

\section{RESULTS}

Colonocyte yield. The yield of isolated colonocytes from the neonatal stool varied between $5 \times 10^{4}$ to $2 \times 10^{6}$ cells/g of stool. Trypan-blue exclusion showed cellular-integrity and viability in an enriched $(70 \%)$ population of the exfoliated cells in stool. There was no difference in viability or number of cells extracted based on the GA of the infant. However, instant processing of stool samples within minutes seemed to result in higher $(>80 \%)$ yield of viable cells; presumably because of the gradual drying of stool in the diaper. Although infant diet (breast- versus formula-fed) showed no statistical correlation, early meconium samples (d 2 and 4 ) resulted in a 10 - to 20-fold higher number of viable cells compared with older infants.

Flow cytometry analysis. Cellular staining and estimation by flow analysis showed increased exfoliation of cells in stool during early days in life. Flow cytometry graphs in Figure 1 display a representative isotype staining (subtracted from the measurements) with increased colonocyte expression of IgA and IgG. A very high percentage of cells were found to express IgA (mean 69\%) throughout the neonatal period. Low to moderate expression of $\mathrm{IgG}$ (mean 24\%) was also observed in these neonates. Although IgG seemed to have a linear increase as the age advanced, it did not reach statistical significance $(p=0.08)$. Figure 2 represents flow cytometry plots showing expression of TLR2, TLR4, and CD45 from gut-derived cell population. As shown in Figure 3, flow analysis revealed about $8 \%$ (range $2-16 \%$ ) of isolated cell population to be of lymphoid origin (CD45 positive). Compared with the mature infants, there was a trend toward higher CD45 positive cells in the immature population. Strikingly, 

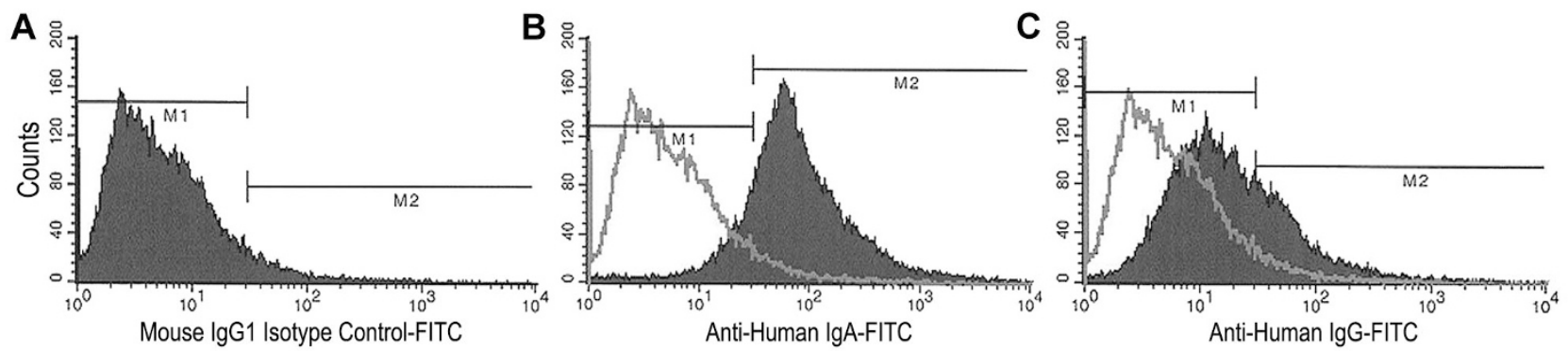

Figure 1. Histograms show flow cytometry results for $\operatorname{IgA}$ and $\mathrm{IgG}$ expression on stool-derived colonocytes from neonates. A representative isotype staining ( $A$; subtracted from measurements) shows increased colonocyte expression of $\operatorname{IgA}(B)$ and linear rise in $\operatorname{IgG}$ levels with infant age $(C)$. M1 represents gated population of unstained cells using the isotype control. M2 represents cells gated for positive staining with either IgA-FITC or IgG-FITC antibodies.
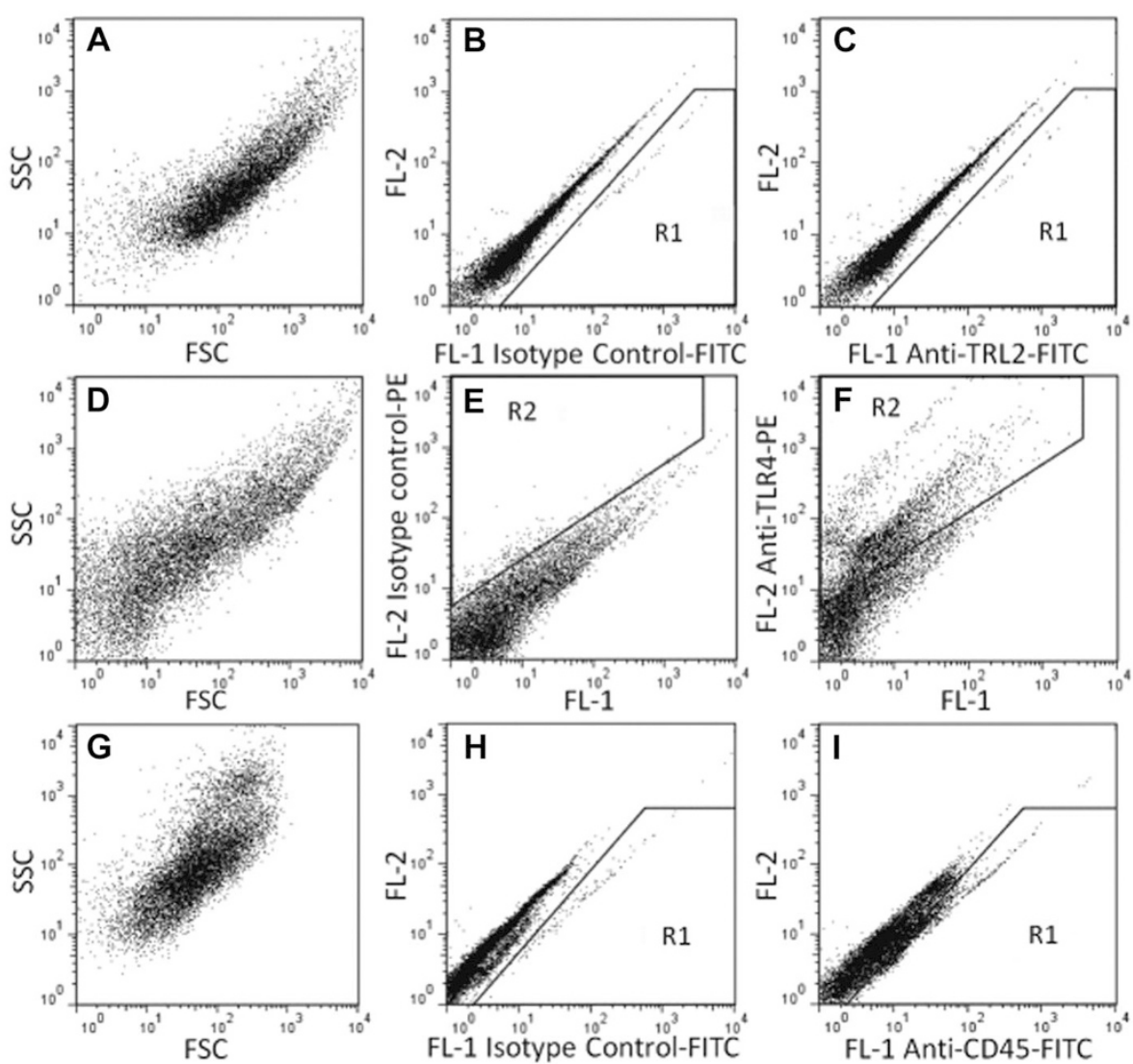

Figure 2. Representative flow cytometry dot plots showing expressions of TLR2, TLR4, and CD45. Column 1 shows the forward (FSC) and side scatter (SSC) plots of the isotype control (A, $D$, and $G$ ); column 2 shows the FL1-FL2 plot of isotype staining (control) from which a region gate is drawn $(B, E$, and $H)$, and column 3 shows the stained sample. In the FL1-FL2 plots in column 3, a rightward shift into region R1 indicates a FITC signal shift relative to the control, and an upward shift into region R2 indicates a PE signal shift relative to the control. Only a very small percentage of cells $(\approx 1 \%)$ were positive for TLR2 $(C)$ in contrast to about $55 \%$ showing TLR4 specific staining $(F)$. Moderately low number $(\approx 8 \%)$ of $\mathrm{CD} 45+$ cells are shown in this infant $(I)$. majority of the exfoliated cells in newborns lacked TLR2 staining, whereas about 55\% (range 17-70\%) of the cells revealed TLR4 expression (Fig. 3).

Quantitative real-time PCR. An overview of the target genes amplified using specific primer sequences and average amplification cycles at which fluorescent signals were detected is shown in Table 1. Using colonocyte RNA from infants representing different age groups, qRT-PCR showed amplification of all three genes- cytokeratin-19: a reference marker for epithelial lineage; $Z O-1$ : a $\mathrm{Tj}$ protein; and the ribosomal protein-24: a house keeping mammalian gene, expressed in neonatal colonocytes. Figure 4 shows reproducibility of qRT-PCR with amplification signals of individual samples analyzed for presence of all three genes. Early and specific signals for the presence of cytokeratin-19 expression in all samples consistently demonstrated epithelial lineage of these live cells in stool. Although we observed no differences among samples based on age, these genes could be amplified with high level of specificity using neonatal colonocytes.

\section{DISCUSSION}

In this study, we describe a noninvasive method to obtain highly enriched viable population of colonic cells in stool from premature neonates, adopting a modified protocol that can efficiently recover between $5 \times 10^{4}$ to $2 \times 10^{6}$ cells $/ g m$ of stool. Adding a selective treatment step, early fecal samples including meconium resulted in highly enriched population of live colonic cells compared with older infants. Meconium can be a rich source of these cells making it an attractive nonin- 

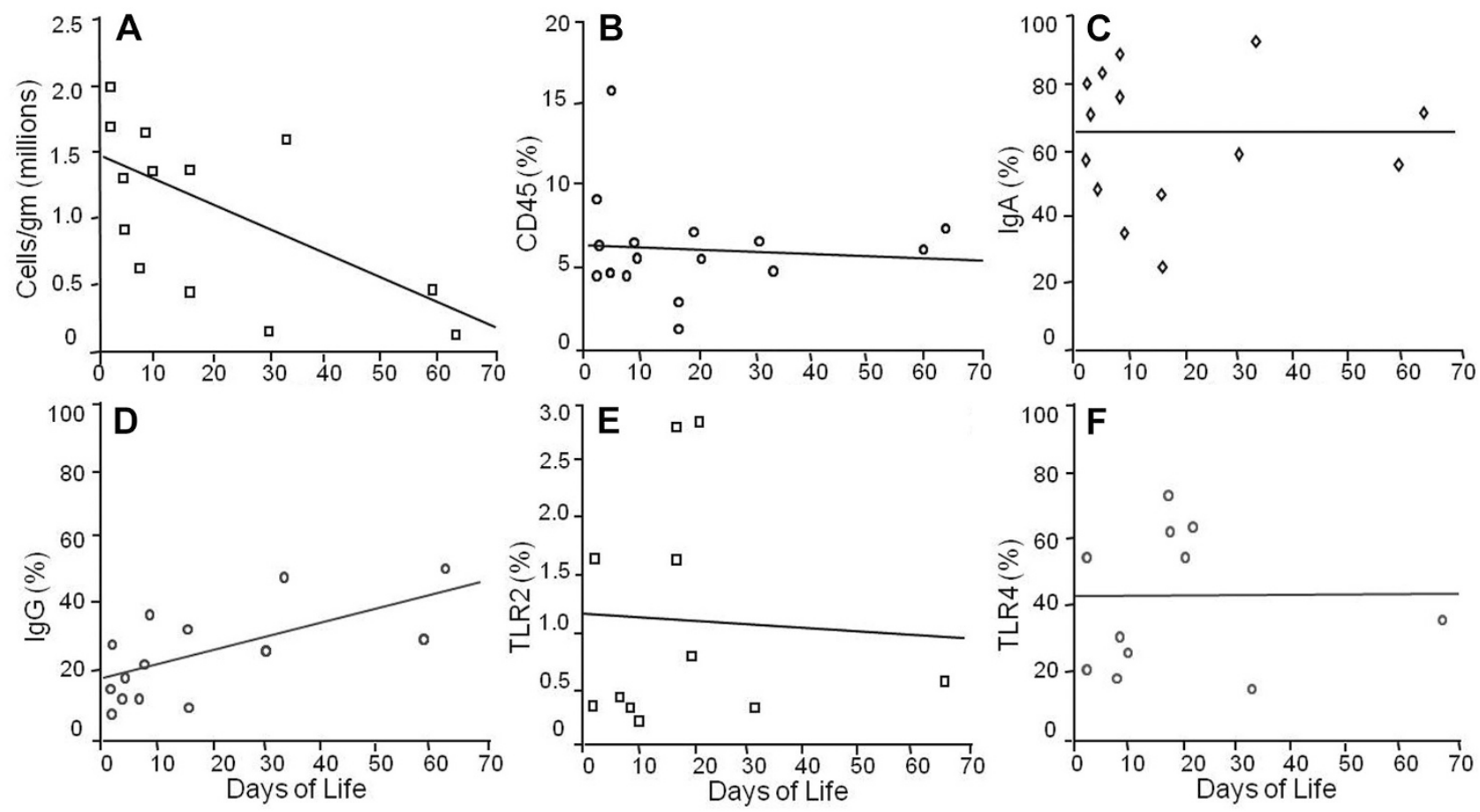

Figure 3. Flow cytometry analysis of colonocyte expression: percentage of positive cells (expression) matched with age of infants. (A) Average yield of colonocytes obtained from stool samples of premature neonates at different time points. Colonocyte yield varied between $5 \times 10^{4}$ and $2 \times 10^{6}$ cells/g of stool. Significantly higher number of viable cells were recovered from stool during early days in life and in meconium $(p<0.05)$. $(B)$ Cells showed a trend toward high CD-45 positive cells early in life demonstrating the presence of intraepithelial lymphocytes and cells of lymphoid origin from possible minor bleeds in the newborn gut. (C) A high percentage of cells were found to express IgA (mean 69\%) throughout the neonatal period. $(D)$ Cells showed low to moderate expression of IgG (mean 24\%). Although IgG seemed to have a linear increase as the age advanced, it did not reach significance $(p=0.08)$. $(E)$ There was an almost total lack of TLR2 staining in contrast to TLR4 $(F)$, an average of near 55\% colonocytes were shown positive.
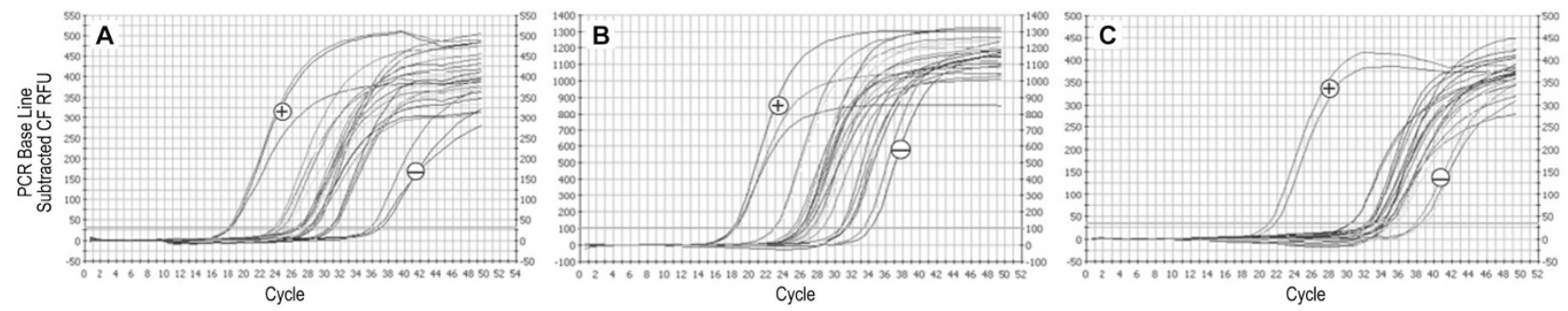

Figure 4. qRT-PCR on colonocyte RNA from infant stool samples representing different age groups. Epithelial lineage-specific marker: cytokeratin-19 (A); the common eukaryotic genes: ribosomal protein-24 (B); and Tj protein: ZO-1(C) displayed a range of amplification signals invariably detected between 16 and 20 cycles. Although no difference was observed among the samples based on age in this preliminary study, qRT-PCR results indicate that these common genes from colonocytes isolated from premature neonates can be amplified with high level of specificity. The multicurves (fluorescent signals) in all three graphs represent individual sample RNA amplification profiles compared with standard RNA preparations from cultured Caco-2 cells as positive control (+) and PCR negative controls (-) devoid of any amplification target.

vasive approach to study markers of intrauterine and newborn gut maturation.

Colonic epithelial cells once exfoliated into the fecal stream assume a globular shape and are protected by a thick layer of a glycocalyx as observed in ultrastructural studies (1). These cells, appearing functionally "dormant," can retain their characteristic cell surface antigenic motifs and may become activated in the presence of appropriate ligands (agonists) (1). The freshly isolated cells reflect a picture of the immediate history of the gut function and its environment, retaining their original gene expression profiles during transit via colon. The sample transport medium used in our study was originally formulated to preserve the epithelial cells in stool in a viable state for up to $5-6 \mathrm{~d}$ at ambient temperature. It is a nontoxic medium that while preserving cell integrity arrests metabolic activities, DNA replication, and mRNA expression and inhibits nucleases and neuraminidase (1). These cells, shown to express blood group antigens indicate their origin in proximal segments (distal segment do not express blood group antigens) and confirms their survival through transit and retention of their regional characteristics (9).

In a recent review comparing human colonocyte studies (5,7-9,16-18) based on Percoll-gradient separation and immunomagnetic bead-based assays, Loktionov (13) observed low yield and poor integrity of the isolated cells as a common problem. Although techniques involving immunomagnetic 
beads seemed to be superior in some reports (8), they lacked optimization with varying results when subjected to DNA/ RNA assessment and gut-gene expression analysis $(16,17)$. However, in line with our findings, more recent reports $(3,14)$ now clearly demonstrate that these techniques do offer a reliable platform for extracting nuclear material from the exfoliated cell population in stool to study gut markers in neonates.

Exfoliated colonocytes in adult stool have been shown to be useful in early detection and prognosis of colon cancer $(1,7,9)$. Using colonocyte DNA, Onouchi et al. (10) have performed mutation analysis for early detection of colorectal cancer. Gene sets identified in fecal mRNA from exfoliated cells has enabled investigators to distinguish between breast-fed and formula-fed infants (14). Although these studies clearly support the utility of exfoliated colonocytes in stool, gut surface markers in developing newborn gut have not been described using the noninvasive techniques.

This study of cellular markers by flow cytometry and genetic analysis by qRT-PCR further support the utility of exfoliated colonocytes in stool as a potential tool to study gut markers in developing neonates. Apart from cytokeratin-19 specific amplification in all samples indicating epithelial origin of isolated colonic cells, we noticed several key observations in this study: 1) Meconium is a very rich source of live colonocytes and can be an ideal sample to study both fetal and newborn gut pathophysiology. 2) Exfoliated cells as early as d 2 express high levels of $\operatorname{IgA}$, with a low to moderate expression of IgG. 3) Intraepithelial lymphocytes are probably the source of the small number of CD45 positive cells in stool, although minor bleeds in the leaky newborn gut cannot be ruled out. 4) Colonocytes of preterm neonates may lack TLR2 expression, however, $>55 \%$ of the cells expressed TLR4. Moreover, exfoliated epithelial cells should be distinguished from cells of other (lymphoid) lineages that are unrelated to gut exfoliation. Notably, our observation of CD45 positive cell population, traced as cells of lymphoid origin, can serve as a marker of inflammation and disease.

Colonocytes obtained from early neonatal period (d 2) showed elevated IgA expression. Other prospective studies have shown early physiological increase in salivary $\operatorname{IgA}$ in formula-fed than in breast-fed infants (19). This may be a natural protective mechanism against colonizing pathogens in the newborn triggered by yet unknown factors when the formula-fed infant is deprived of breast-milk IgA. However, we also observed a linear rise in IgG levels in these cells, with infants' age, probably because of the exposure to the colonizing microbes in the gut. It is logical to speculate that exposure to bacterial world during early infancy may have a significant impact on $\operatorname{IgA}$ and $\operatorname{IgG}$ expression later in life.

Using flow cytometry, Nair et al. (1) first described functional diversity of colonocytes purified from adult stool showing surface expression of $\operatorname{IgG}, \operatorname{IgA}$, and the secretory component. Expression of $\operatorname{IgG}$ have also been reported in colonic cancer cells $(20,21)$. Previous studies with cultured epithelial cells have shown surface expression of Fc fragment of IgG (IgG-Fc) binding sites $(22,23)$. The intestinal epithelial cells (IECs), as nonprofessional antigen-presenting cells (APC), can take up and process antigens activating CD8 + regulatory $\mathrm{T}$-cell subsets in a nonclassical major histocompatibility complex-1 (MHC I) restricted manner (24). The IECs work as the first line of defense against the heavy load of bacteria in the gut. These cells have been shown to constitutively and inducibly express several functional TLRs (25) in vitro and in vivo, including TLR2 (ligands, e.g. peptidoglycan and lipoproteins), TLR4 [lipopolysaccharide (LPS)]s, and TLR9 [methylated sequences in DNA significant in gene regulation (CpG DNA)] (26-28). In a recent study in WT mice, differential expression of colonic TLR2 and TLR4 along the proximal-distal axis has been mainly attributed to significant differences in the community structure and diversity of mucosa-associated microbiota located in the distal and proximal colon (29).

Cario et al. (30) have shown that colonocytes of preterm neonates may lack TLR2 expression and may be vulnerable to Tjs damage. However, high level of TLR4 expression may further provide a suitable niche for Gram-negative or LPSmediated damage in these cells. Fusunyan et al. (31) have described constitutive expression of TLR 2 and TLR 4 on the basolateral surface of fetal crypt enterocytes (H4 small intestinal cells). In their study, IL- $1 \beta$ increased both TLR 2 and TLR 4, whereas LPS decreased TLR 4 in these enterocyte-like $\mathrm{H} 4$ cells (31). More recently, direct involvement of TLRs and nucleotide-binding oligomerization domain-2 (NOD2) has been shown in NEC (32). Activation of TLR2 leads to enhancement of ZO-1-associated intestinal epithelial barrier integrity (33). Oral supplementation with TLR2 ligand proprotein convertase subtilisin/kexin (PCSK) significantly suppressed mucosal inflammation and apoptosis by restoring $\mathrm{Tj}$ integrity in this study. Other TLR2 inducing Grampositive commensals and probiotics have also been reported in maintaining intestinal mucosal homeostasis against tissue injury (34-37).

In conclusion, our study highlights a noninvasive method for purifying viable colonic cells from stool of neonates. Higher number of these cells recovered in early stool and meconium samples further substantiates utility of these cells in designing postnatal screening/diagnostic tests for the study of neonatal gut maturation. Isolated colonocytes can be used for the detection of the surface antigens by flow cytometry and the study of gene expression by RT-PCR. Gene expression analysis can help to monitor group of genes, whose expression changes early in gut maturation and disease onset, during postnatal life. Larger studies on these colonic cells, exploring multitarget assay panels and gene expression signature patterns, may allow molecular classifications of gut maturation and disease pathogenesis. Future expression microarray and epigenetic approaches involving colonic cells, and studies targeting gut-specific responses to bacterial colonization comparing healthy and inflamed gut, may provide clues to pathogenic insights and disease progression in developing human neonates.

\section{REFERENCES}

1. Nair P, Lagerholm S, Dutta S, Shami S, Davis K, Ma S, Malayeri M 2003 Coprocytobiology: on the nature of cellular elements from stools in the pathophysiology of colonic disease. J Clin Gastroenterol 36:S84-S93 
2. Kamra A, Kessie G, Chen JH, Kalavapudi S, Shores R, McElroy I, Gireesh T, Sudhakaran PR, Dutta SK, Nair PP 2005 Exfoliated colonic epithelial cells: surrogate targets for evaluation of bioactive food components in cancer prevention. J Nutr 135:2719-2722

3. Kaeffer B, des Robert C, Alexandre-Gouabau MC, Pagniez A, Amarger V, Legrand A, Kuster A, Piloquet H, Champ M, Le Huarou-Luron I, Roze J-C 2007 Recovery of exfoliated cells from the gastrointestinal tract of premature infants: a new tool to perform "noninvasive biopsies?" Pediatr Res 62:564-569

4. Bader GM, Papanicolaou GN 1952 The application of cytology in the diagnosis of cancer of the rectum, sigmoid, and descending colon. Cancer 5:307-314

5. Iyengar V, Albaugh GP, Lohani A, Nair PP 1991 Human stools as a source of viable colonic epithelial cells. FASEB J 5:2856-2859

6. Lagerholm S, Dutta S, Nair PP 2005 Noninvasive detection of c-myc p64, c-myc p67 and c-erbb-2 in colorectal cancer. Scand J Gastroenterol 40:1343-1350

7. Yamao T, Matsumura Y, Shimada Y, Moriya Y, Sugihara K, Akasu T, Fujita S, Kakizoe T 1998 Abnormal expression of CD44 variants in the exfoliated cells in the feces of patients with colorectal cancer. Gastroenterology 114:1196-1205

8. Matsushita H, Matsumura Y, Moriya Y, Akasu T, Fujita S, Yamamoto S, Onouch S, Saito N, Sugito M, Ito M, Kozu T, Minowa T, Nomura S, Tsunoda H, Kakizoe T 2005 A new method for isolating colonocytes from naturally evacuated feces and its clinical application to colorectal cancer diagnosis. Gastroenterology 129:19181927

9. Albaugh GP, Iyengar V, Lohani A, Malayeri M, Bala S, Nair PP 1992 Isolation of exfoliated colonic epithelial cells, a novel noninvasive approach to the study of cellular markers. Int J Cancer 52:347-350

10. Onouchi S, Matsushita H, Moriya Y, Akasu T, Fujita S, Yamamoto S, Hasegawa H, Kitagawa Y, Matsumura Y 2008 New method for colorectal cancer diagnosis based on SSCP analysis of DNA from exfoliated colonocytes in naturally evacuated feces. Anticancer Res 28:145-150

11. Davidson LA, Lupton JR, Miskovsky E, Fields AP, Chapkin RS 2003 Quantification of human intestinal gene expression profiles using exfoliated colonocytes: a pilot study. Biomarkers 8:51-61

12. Ahmed FE, James SI, Lysle DT, Dobbs LJ, Johnke RM, Flake G, Stockton P, Sinar DR, Naziri W, Evans MJ, Kovacs CJ, Allison RR 2004 Improved methods for extracting RNA from exfoliated human colonocytes in stool and RT-PCR analysis. Dig Dis Sci 49:1889-1898

13. Loktionov A 2007 Cell exfoliation in the human colon: myth, reality and implications for colorectal cancer screening. Int J Cancer 120:2281-2289

14. Chapkin RS, Zhao C, Ivanov I, Davidson LA, Goldsby JS, Lupton JR, Mathai RA Monaco MH, Rai D, Russell WM, Donovan SM, Dougherty ER 2010 Noninvasive stool-based detection of infant gastrointestinal development using gene expression profiles from exfoliated epithelial cells. Am J Physiol Gastrointest Liver Physio 298:G582-G589

15. Panigrahi P, Braileanu GT, Chen H, Stine OC 2007 Probiotic bacteria change Escherichia coli-induced gene expression in cultured colonocytes: Implications in intestinal pathophysiology. World J Gastroenterol 13:6370-6378

16. Loktionov A, O'Neill IK, Silvester KR, Cummings JH, Middleton SJ, Miller R 1998 Quantitation of DNA from exfoliated colonocytes isolated from human stool surface as a novel noninvasive screening test for colorectal cancer. Clin Cancer Res 4:337-342

17. Bandaletova T, Bailey N, Bingham SA, Loktionov A 2002 Isolation of exfoliated colonocytes from human stool as a new technique for colonic cytology. APMIS 110:239-246

18. Spethmann S, Fisher C, Wagener C, Streichert T, Tschentscher P 2004 Nucleic acids from intact epithelial cells as a target for stool-based molecular diagnosis of colorectal cancer. Int J Mol Med 13:451-454
19. Brandtzaeg P, Nilssen DE, Rognum TO, Thrane PS 1991 Ontogeny of the mucosal immune system and IgA deficiency. Gastroenterol Clin North Am 20:397-439

20. Qiu X, Zhu X, Zhang L, Mao Y, Zhang J, Hao P, Li G, Lv P, Li Z, Sun X, Wu L, Zheng J, Deng Y, Hou C, Tang P, Zhang S, Zhang Y 2003 Human epithelial cancers secrete immunoglobulin-G with unidentified specificity to promote growth and survival of tumor cells. Cancer Res 63:6488-6495

21. Chen Z, Gu J 2007 Immunoglobulin G expression in carcinomas and cancer cell lines. FASEB J 21:2931-2938

22. Kobayashi K, Brown WR 1994 Study of colonic IgG Fc binding site in cultured epithelial cells. Dig Dis Sci 39:526-533

23. Harada N, Iijima S, Kobayashi K, Yoshida T, Brown WR, Hibi T, Oshima A, Morikawa M 1997 Human IgGFc binding protein (Fc $\gamma \mathrm{BP}$ ) in colonic epithelial cells exhibits mucin-like structure. J Biol Chem 272:15232-15241

24. Perera L, Shao L, Patel A, Evans K, Meresse B, Blumberg R, Geraghty D, Groh V, Spies T, Jabri B, Mayer L 2007 Expression of non-classical class I molecules by intestinal epithelial cells. Inflamm Bowel Dis 13:298-307

25. Cario E 2002 Toll-like receptors and gastrointestinal diseases: from bench to bedside? Curr Opin Gastroenterol 18:696-704

26. Abreu MT, Arnold ET, Thomas LS, Gonsky R, Zhou Y, Hu B, Arditi M 2002 TLR4 and MD-2 expression is regulated by immune-mediated signals in human intestinal epithelial cells. J Biol Chem 277:20431-20437

27. Akhtar M, Watson JL, Nazli A, Mckay DM 2003 Bacterial DNA evokes epithelial IL-8 production by a MAPK-dependent, NF-kappaB-independent pathway. FASEB J 17:1319-1321

28. Cario E, Brown D, McKee M, Lynch-Devaney K, Gerken G, Podolsky DK 2002 Commensal-associated molecular patterns induce selective toll-like receptortrafficking from apical membrane to cytoplasmic compartments in polarized intestinal epithelium. Am J Pathol 160:165-173

29. Wang Y, Devkota S, Musch MW, Jabri B, Nagler C, Antonopoulos DA, Chervonsky A, Chang EB 2010 Regional mucosa-associated microbiota determine physiological expression of TLR2 and TLR4 in murine colon. PLoS ONE 5:e13607

30. Cario E, Gerken G, Podolsky DK 2007 Toll-like receptor 2 controls mucosal inflammation by regulating epithelial barrier function. Gastroenterology 132:13591374

31. Fusunyan RD, Nanthakumar NN, Baldeon ME, Walker WA 2001 Evidence for an innate immune response in the immature human intestine: toll-like receptors on fetal enterocytes. Pediatr Res 49:589-593

32. Le Mandat Schultz A, Bonnard A, Barreau F, Aigrain Y, Pierre-Louis C, Berrebi D, Peuchmaur M 2007 Expression of TLR-2, TLR-4, NOD2 and pNF-kappaB in a neonatal rat model of necrotizing enterocolitis. PLoS One 2:e1102

33. Cario E, Gerken G, Podolsky DK 2004 Toll-like receptor 2 enhances ZO-1 associated intestinal epithelial barrier integrity via protein kinase C. Gastroenterology 127:224-238

34. Rakoff-Nahoum S, Paglono J, Eslami-Varzaneh F, Edberg S, Medzhitov R 2004 Recognition of commensal microflora by toll-like receptors is required for intestinal homeostasis. Cell 118:229-241

35. Otte JM, Podolsky DK 2004 Functional modulation of enterocytes by gram-positive and gram-negative microorganisms. Am J Physiol Gastrointest Liver Physiol 286:G613-G626

36. Madsen KL 2001 The use of probiotics in gastrointestinal disease. Can J Gastroenterol 15:817-822

37. Petrof EO, Kojima K, Ropeleski MJ, Musch MW, Tao Y, De Simone C, Chang EB 2004 Probiotics inhibit nuclear factor Kappa B and induce heat shock proteins in colonic epithelial cells through proteasome inhibition. Gastroenterology 127:14741487 